Portland State University

PDXScholar

\title{
Using "Remote" Training and Coaching to Increase Providers' Skills for Working Effectively with Older Youth and Young Adults with Serious Mental Health Conditions
}

\author{
Janet S. Walker \\ Portland State University, janetw@pdx.edu \\ Caitlin Baird \\ Portland State University
}

Follow this and additional works at: https://pdxscholar.library.pdx.edu/socwork_fac

Part of the Community Health Commons, and the Social Work Commons Let us know how access to this document benefits you.

\section{Citation Details}

Walker, Janet S. and Baird, Caitlin, "Using "Remote" Training and Coaching to Increase Providers' Skills for Working Effectively with Older Youth and Young Adults with Serious Mental Health Conditions" (2019). Social Work Faculty Publications and Presentations. 310.

https://pdxscholar.library.pdx.edu/socwork_fac/310

This Post-Print is brought to you for free and open access. It has been accepted for inclusion in Social Work Faculty Publications and Presentations by an authorized administrator of PDXScholar. Please contact us if we can make this document more accessible: pdxscholar@pdx.edu. 
[This is an accepted manuscript of an article published by Elsevier in Children \& Youth Services Review May 2019, available online:

https://doi.org/10.1016/j.childyouth.2019.02.040]

\title{
Using "Remote" Training and Coaching to Increase Providers' Skills for Working Effectively with Older Youth and Young Adults with Serious Mental Health Conditions
}

\author{
Janet S. Walker \& Caitlin Baird
}

\begin{abstract}
Since about the turn of the century, a growing awareness of the poor outcomes resulting from "as usual" community mental health care has led to increasing efforts to implement programs and interventions with empirical evidence of effectiveness. However, these efforts have encountered numerous barriers, in particular the high cost of implementation, which has severely limited uptake and sustainment of empiricallysupported programs and interventions. Typically, the largest contributor to cost is the training and coaching required to ensure provider competence and fidelity to the intervention or program model. This paper describes a social innovation that aims to provide high-quality training and coaching that is affordable and sustainable in community mental health settings. The main strategy for this is the use of a completely "remote" process for training and coaching. This process relies on a web-based platform through which trainees access a library of real examples of good-and not-so-good-practice, and through which they also receive individualized coaching and feedback based on video recordings of their own practice with clients. Specifically, the paper describes a remote training intervention for practitioners working with young people aged 16-25 who experience serious mental health conditions. This approach is designed to train providers to work with young people in ways that increase their engagement and retention in services, as well as their alliance with treatment providers. Enhancing providers' skills in these areas is urgently needed, given that young people in this age range have the highest rates of serious mental health conditions, and yet they are also the least likely to engage in or complete mental health treatment. Findings indicate that participants were highly satisfied with the training, and that their skills in key areas increased significantly, as measured both by their own subjective assessment and by expert ratings of their video-recorded practice.
\end{abstract}

\section{Introduction}

\section{Social Innovation as Applied to Training for Mental Health Providers}

Since about the turn of the century, a growing awareness of the poor outcomes resulting from "as usual" community mental health care has led to increasing efforts to implement programs and interventions with empirical evidence of effectiveness (e.g., Barth et al., 2011; Drake, et al., 2001; Garland et al., 2013; Weisz, Jensen-Doss, \& Hawley, 2006). Training mental health practitioners to work with clients in these new ways presents substantial challenges, however. Ample research shows that, in order for mental health practitioners to become 
competent in new approaches for working with clients, workshop-based training and the provision of manuals and other supportive materials (the most common training modality in community mental health settings) is insufficient to create sustained practice change (Edmunds, Beidas, \& Kendall, 2013; Powell, Proctor, \& Glass, 2013; Rakovshik \& McManus, 2010; Stirman, Langdon, \& Graham, 2016). In order to ensure the transfer of training into practice, it is crucial that initial training is followed by highquality, practice-focused coaching over a period of at least several months (Edmunds et al., 2013; Goense, Boendermaker, \& van Yperen, 2016; Martino et al., 2016). Coaching during the implementation of new practices is often provided by outside specialists, however, it can also be provided by supervisors or expert peers, provided they have both coaching skill and practice expertise. High-quality coaching requires several specific elements, including observation of trainees as they use the practice (either live or via audio or video recording) with subsequent individualized feedback that is reliable and based on objective criteria (Dorsey et al., 2013; Garland et al., 2013; Herschell, Kolko, Baumann, \& Davis, 2010; Milne, Sheikh, Pattison, \& Wilkinson, 2011; Powell et al., 2013). It is crucial that coaches not rely primarily on trainees' reports of their own practice, since people generally (Kruger \& Dunning, 1999), and mental health providers specifically (Martino, Ball, Nich, Frankforter, \& Carroll, 2009; Olmstead, Abraham, Martino, \& Roman, 2012), tend to be extremely inaccurate judges of their own level of competence.

The costs of providing high-quality training and coaching can dissuade agencies from implementing and sustaining new practice approaches. For example, purveyors of evidence-based practices typically provide high-quality training and coaching as part of the package of implementation supports that agencies are required to purchase. Newer studies have begun to yield information about the magnitude of these costs, with cognitive-behavioral therapy (CBT, one of the most frequently implemented evidence-based practices) being perhaps the best studied. Examining trauma-focused CBT costs in ten clinics, a recent investigation found that initial 10-month implementation costs averaged USD $\$ 89,575$ per agency, $\$ 11,659$ per participating staff member, and \$2,745 per child treated (Lang \& Connell, 2017). Another study examined ongoing costs to sustain the same intervention across 14 clinics, and found yearly costs of $\$ 65,192$ per clinic, $\$ 4,461$ per staff member trained, and $\$ 1,896$ per child treated (Roundfield \& Lang, 2017). Clearly, these kinds of costs can deter agencies from implementing new practices, or cause agencies to discontinue the use of new practices after initial implementation (Aarons, Wells, Zagursky, Fettes, \& Palinkas, 2009; Bond et al., 2014). In fact, Bond et al. (2014) found that cost was the top reason for discontinuation of an evidence-based practice, and that fewer than half of community agencies sustained an evidencebased practice over six years. Looking specifically at training for providers working with emerging adults with serious mental health conditions, Jivanjee et al. (2018) found cost to be the most frequently endorsed barrier preventing providers from receiving the training they needed.

The need to close the gap between what works and what can feasibly be implemented presents a ripe opportunity for social innovation. As defined by Sinclair and Baglioni (2014), a social innovation is a "distinctive and effective response to address unmet needs motivated by a social purpose which enhances social assets and capabilities." Social innovation is seen as holding promise to revitalize human services and to address intractable social problems. In the case of community mental health services, efforts to provide affordable, effective training for practitioners have prompted stirrings of social innovation in the form of new, technology-enabled training strategies and modalities. One set of strategies relies on creative uses of technology to reduce costs and to allow for training experiences that reflect best practices (Parsons \& Reid, 2012). For example, providing "live" trainings partially or fully via web conference can eliminate the costs associated with travel for both trainees and trainers. What is more, 
when travel costs are eliminated, so is the imperative to deliver training in the smallest possible number of consecutive days, which is inconsistent with a highquality approach to training as described previously. Instead, training can be spread out over a period of months, and trainees learn and practice basic skills before moving on to more advanced skills. Web-based platforms can also make it possible for trainees to "observe" real practice by accessing online video recordings of experts using the approach. Web-based technology can also be used to facilitate the use of audio or video "observation," with trainees uploading samples of their practice for review by coaches and/or supervisors. This process can offer savings over in-person observation and coaching by eliminating travel and other costs stemming from having expert coaches shadow trainees as they go about their work.

Another innovative strategy with potential to increase overall workforce skills while also reducing training costs is one that capitalizes on the fact that mental health interventions often share core attributes. For example, many empirically-supported treatments share key common elements or components, such as psychoeducation, exposure, guided imagery or behavioral rehearsal, etc. This means that providers can be trained on the practice elements that appear frequently as constituents of separate evidence-based and empirically-supported interventions, and then can then apply these elements flexibly to meet individual client needs. This approach has been used successfully for responding to children's emotional and behavioral challenges (e.g., Bruns et al., 2014; Chorpita, Bernstein, \& Daleiden, 2011; Chorpita, Daleiden, \& Weisz, 2005; Weisz et al., 2012). In addition to shared elements, effective mental health interventions are also characterized by common factors or attributes of the providerclient relationship (e.g., Barth et al., 2011; Mitchell, 2011; Weisz, Jensen-Doss, \& Hawley, 2006). The best studied of these is therapeutic alliance, which is strongly linked to client engagement and positive outcomes from mental health interventions (Ardito \& Rabellino, 2011), specifically including youth and young adult clients (Hawley \& Garland, 2008; Shirk
\& Karver, 2003; Zack, Castonguay, \& Boswell, 2007). Looked at as a whole, these kinds of studies suggest that cost-effectiveness of overall training for providers may be enhanced by ensuring that they are adept in common aspects that span multiple empiricallysupported practices, and can provide a structure for both what to do to (i.e., common elements) and how to do it (i.e., common factors).

\section{The Need for Effective Mental Health Services for Older Youth and Young Adults}

Increasingly in the United States and other developed nations, there is consensus that the age from about 16 to 25 represents a distinct phase of life, with its own set of developmental markers and challenges (Arnett, 2000, 2007; Baggio, Studer, Iglesias, Daeppen, \& Gmel, 2016; Rosenberg, 2016). In the United States, young people in this phase of life generally report high levels of well-being (Stone, Schwartz, Broderick, \& Deaton, 2010). However, they also experience the highest levels of stress and the highest rates of mental health conditions (Stone et al., 2010; Substance Abuse and Mental Health Services Administration, 2018). Among young adults in the US, both the percentage having a serious mental health condition and the percentage having any mental health condition are rising, and this trend appears to be accelerating (Substance Abuse and Mental Health Services Administration, 2018). At the same time, there is a growing body of research showing that young adults are the age group least likely to engage in mental health services, at least in part because the services and supports that are available tend to be neither engaging nor developmentally optimal (Kim, Munson, \& McKay, 2012; Moore, 2018; Pottick, Bilder, \& Vander Stoep, 2008; Stewart, 2013; Substance Abuse and Mental Health Services Administration, 2018; US Government Accountability Office, 2008).

\section{Common Elements and Common Factors in Interventions for Youth and Young Adults}

In response to this gap between need and uptake, researchers and service providers have begun developing new approaches to mental health care 
that are designed specifically to meet the unique needs of emerging adults. A small number of these approaches have been tested to the extent that they can be described as "empirically supported" (i.e., supported by evidence; Walker and Gowen, 2011, Walker and Gowen, 2012; Walker, Brennan, Jivanjee, Koroloff, \& Moser, 2015). Other research and evaluation efforts have focused on adapting and testing existing approaches that are evidence-based for children or adolescents, or for "older" adults. As is the case with other empirically-supported programs in mental health, however, implementation and training costs inhibit widespread implementation.

Both the new and adapted approaches tend to share a core set of key practice principles that reflect a positive developmental approach (Catalano, Berglund, Ryan, Lonczak, \& Hawkins, 2004; Lerner, Brentano, Dowling, \& Anderson, 2002; Walker, Seibel, Jackson, \& Ossowski, 2016), and that are presumed to promote engagement, good working relationships, and the activation of change processes (Walker, 2015; Walker \& Gowen, 2011). These principles can be thought of as the common factors identified for working successfully with the population. Specifically, these principles encourage practitioners to work with emerging adults in ways that are strengths based and driven by the young person's perspectives and priorities. Additional shared principles stress the importance of helping young people to acquire self-determination skills, and to develop skills for building relationships and/or social capital, through connections to supportive adults and peers, and through connections to development-enhancing contexts (Ellison et al., 2015; Institute of Medicine and National Research Council, 2015; Walker, 2015). Beyond shared principles, these approaches also tend to share core intervention components (i.e., common elements) as well. Specifically, person-centered planning was a key shared activity within most of these approaches.

However, research focused on mental health services for emerging adults suggests that, even when providers are working within programs and interventions that are grounded in these practice principles, their actual practice often does not reflect the principles. In fact, providers often appear confused or uncertain regarding how to translate the abstract principles into concrete interactions with young people (Haber, Cook, \& Kilmer, 2012; Walker \& Flower, 2015; Walker, Pullmann, Moser, \& Bruns, 2012; Walker \& Schutte, 2005). Similarly, despite the widespread use of person-centered planning as a core component of human services interventions, research studies have documented a lack of specification of, and quality control over, the process as it is implemented with clients (Miller, Stanhope, Restrepo-Toro, \& Tondora, 2017; Taylor \& Taylor, 2013). Taken together, these studies suggest the need not only to invest in interventions and programs that are potentially effective, engaging and developmentally appropriate for emerging adults (Clark \& Unruh, 2009; Haber, Karpur, Deschênes, \& Clark, 2008; Stein, Connors, Chambers, Thomas, \& Stephan, 2014), but also to enhance the skills of providers that are charged with implementing these approaches, so that they are able to execute interventions in a way that reflects best practices and practice principles.

\section{An Innovation for Training Mental Health Providers}

This paper describes a study of a training project that aimed to explore an innovative strategy for enhancing providers' skills in engaging and working effectively with emerging adults with serious mental health conditions. All of the participating providers were working within their youth and young adult clients using interventions that had person-centered planning at the core. Further, all of the interventions prescribed shared principles as enumerated previously: the planning process was to be youth-/young adult-driven and strengths-based, and focused on building self-determination and connections to the community. Thus, the training project combined the two types of potentially cost-effective innovations described previously. First, the training focused on enhancing providers' existing skills for both common elements (i.e., the steps in a structured process of person-centered planning) and common factors (i.e., skills for implementing the positive developmental practice principles described previously). Further, 
the entire training was done remotely, using a combination of technologies to implement a process that incorporated training best practices. The study tests the hypothesis that the training approach can significantly increase providers' skills from pre- to post-training. The study also examines two research questions. First, how satisfied were trainees with various aspects of the training? And second, what are the biggest barriers, and what is most helpful, in implementing practice change?

\section{Method}

\section{Participants}

Data for this study were collected from 63 providers who participated in the Achieve My Plan skills enhancement training intervention. The providers were all bachelors or masters level clinicians whose work focused on transition-aged youth and young adults aged 16 to 21 , using an intensive care coordination and care planning model. The agencies within which these providers worked had been identified in a successful grant proposal focusing on improving outcomes for the population. All of the care coordinators working with youth and young adults within the agencies participated in the training. A total of 77 providers started the training, but 14 of them left the participating agencies and/or changed jobs before completing it. A large majority of the providers $(87.5 \%)$ had been in their current position for more than one year. The intensive care coordination models that the providers were using had a number of shared attributes. Each of the models specified the use of an individualized, strengths-based, person-centered planning process that would promote young people's connections to supportive peers, adults and community contexts (e.g., workplaces, post-secondary training or education, community groups and clubs, etc.). Each of the models also specified that the young people would create their plans in collaboration with a team of supportive allies that would include both professionals (e.g., mental health provider, child welfare case worker, housing specialist) and allies (friends, family), according to the young person's preferences.
The young people that the providers worked with were eligible for intensive care coordination based on having serious mental health conditions and/or being involved with the child welfare system and assessed as having a high risk of poor transition outcomes, particularly homelessness. Eligibility was also predicated on the young people's involvement with two or more youth- and young adult-serving systems, such as mental health, child welfare, special education and juvenile justice/adult corrections.

\section{Procedure}

The AMP skills-enhancement intervention. Achieve My Plan (AMP) is intended to be an enhancement for existing interventions and programs that include a focus on person-centered treatment or care planning with older youth and young adults. AMP is designed to strengthen providers' skills in key areas that are typically needed for working successfully with youth and young adults to create and carry out treatment or care plans (Walker, 2015). Specifically, AMP focuses on increasing providers' skill in promoting young people's acquisition of self-determination skills, and ensuring that care/ treatment is based on their perspectives and priorities, highlights and builds on their strengths in meaningful ways, and promotes their connections to "positive" people and contexts (i.e., people and contexts that support the young person's positive development). Trainees also build their competence in helping young people to mobilize and practice self-determination skills as they carry out activities from their care/treatment plans. These include activities that the young people can carry out on their own in the community, as well as activities that require the young people to work with "facilitators" and "gatekeepers" (i.e., people who can provide access to helpful resources). Treatment or care planning teams (when these are part of the care coordination approach) fall under the general category of facilitators/gatekeepers, and AMP trainees learn how to help young people acquire skills for working with their teams. Trainees also learn how to help the young person determine the "right size" of support that may be needed for any particular activity, and 
how to mobilize needed support from a variety of sources, including family, friends, service providers and other allies and potential helpers.

AMP was originally developed and tested as an enhancement for Wraparound, which is a team-based planning and intensive care coordination process. Wraparound is intended to improve outcomes for children, youth and young adults with the highest levels of mental health and related needs, and their families. Wraparound's first principle stresses that the process should be built around the priorities and perspectives of the young person and their family; however, in practice, the young people's "voice" was often not present to a meaningful extent (Walker et al., 2012; Walker \& Schutte, 2004; Walker, Seibel, \& Jackson, 2017). The AMP enhancement for Wraparound aimed to increase young people's satisfaction, active engagement and self-determined participation in Wraparound, as well as their alliance with their treatment planning team. Findings from a randomized study of AMP (Walker et al., 2017) showed that, relative to youth who received "as usual" Wraparound, young people who received Wraparound with the AMP enhancement participated more-and in a more active and self-determined manner-with their teams. They also rated their alliance with their Wraparound teams significantly higher. Furthermore, adult team members in the intervention condition rated team meetings as being more productive, and they were more likely to say that the AMP meetings were "much better than usual" team meetings. Since its initial development, AMP has been used to enhance providers' skills within other treatment and care planning interventions that include a focus on youth/young adult voice, strengths and self-determination.

AMP training. AMP training is delivered remotely, via a series of web conferences, an internet-based training and coaching platform (the "virtual coaching platform," VCP), and telephone feedback calls (Achieve My Plan, 2018). Eight $1.5 \mathrm{~h}$ small-group interactive web conferences are held bi-weekly over a period of about 4 months, with "homework" assignments completed by trainees in between. Homework includes watching examples of expert and inexpert practice on VCP and/or videorecording samples of their practice with young people and uploading them into VCP for review and scoring by the trainers (Fig. 1).

Figure 1: Screenshot of Video Recording Sample in VCP Software

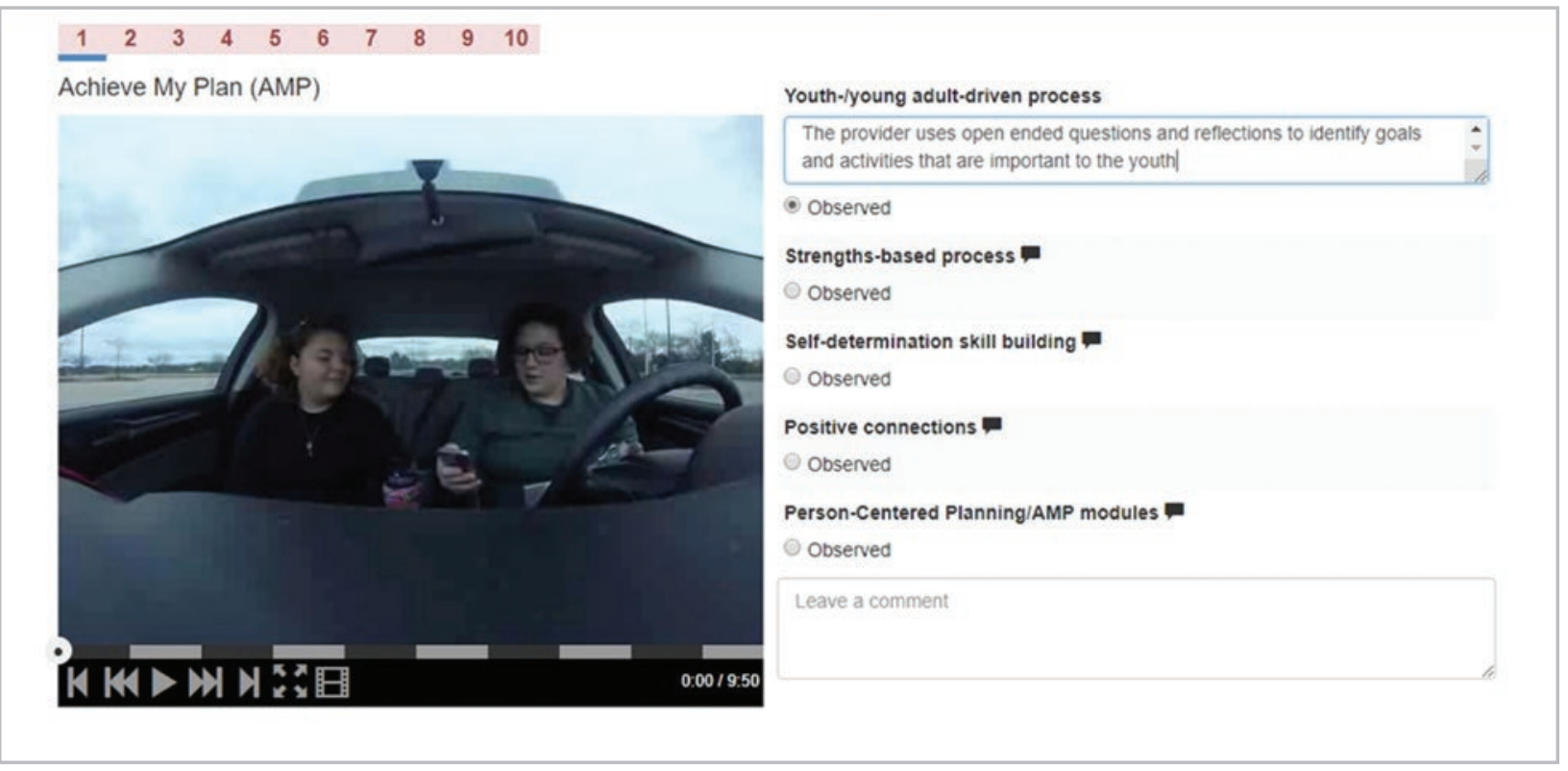


Over the course of the training, each trainee uploads a minimum of eight videos. Two of these are short videos of 5-10 min that focus on the practice of basic skills for active listening. In the remaining six videos (which averaged about $45 \mathrm{~min}$ in length in the current study) trainees are filmed working with young people, going through a series of semi-structured modules that are used to implement person-centered planning. After each video is reviewed, trainees participate in an individualized feedback telephone session that can last up to a half hour, during which the trainer and trainee jointly go over a feedback report the trainer has created in VCP as part of the review and scoring process (Fig. 2). The feedback report includes a description of key practice strengths and "improvables", as well as live links directly to the sections of the uploaded video that exemplify these. The feedback report may also include links to clips that demonstrate skills and techniques that the trainer wants the trainee to review. Most trainees are able to meet benchmark scores (as demonstrated though their video recordings of work with young people from their caseload) by the eighth video; trainees who do not meet benchmark have the opportunity to submit additional videos. Finally, trainees must pass an online quiz to complete the training. All told, the trainees spend about $20 \mathrm{~h}$ participating in the training- and coaching-related activities.

\section{Measures}

The study used two sources of data: online surveys completed by trainees, and scores based on video recordings of trainees' practice uploaded into $\mathrm{VCP}$ as part of the training process.

Online surveys. Trainees completed online surveys at three points in time. The first time point (T1) was just prior to the beginning of the training, the second (T2) was six weeks after the training had begun, and the third (T3) was just after the training had ended. The T1 survey included a self-assessment of skills for using a positive developmental

Figure 2: Screenshot Feedback Report in VCP Software

\begin{tabular}{|c|c|c|}
\hline Feedback Report & & Edit \\
\hline Preparation & Scorer & \multirow{3}{*}{$\begin{array}{l}\text { Created On } \\
\text { Nov. } 29,2018,5.53 \text { p.m. }\end{array}$} \\
\hline Achieve My Plan (AMP) & & \\
\hline \multicolumn{2}{|l|}{ Parameter Comments } & \\
\hline Segment/Parameter & \multicolumn{2}{|l|}{ Feedback } \\
\hline \#1/ Youth-/young adult-driven process & \multicolumn{2}{|c|}{$\begin{array}{l}\text { The provider uses open-ended questions and reflections to identify goals and activities that are important to the youth. The provider asks the } \\
\text { youth if they would like to write and keeps the session conversational } \\
\text { Strengths - open ended questions }\end{array}$} \\
\hline$\# 2$ / Strengths-based process & \multicolumn{2}{|c|}{$\begin{array}{l}\text { The provider uses descriptive praise throughout the section. They also reflect on strengths the youth mentions and stiches them logether with } \\
\text { the youth's identified goals. }\end{array}$} \\
\hline \#2/Improveable & \multicolumn{2}{|c|}{$\begin{array}{l}\text { When the youth mentions wanting to focus on finding a job, the provider should offer a reflection on such, and use open ended questions to } \\
\text { see if the youth wants to explore that goal right now, for instance "It sounds like finding a job is where your focus is right now, do you want to } \\
\text { work on that today?" } \\
\text { improvables - missed opportunity }\end{array}$} \\
\hline \#4/Sell-determination skill building & \multicolumn{2}{|c|}{$\begin{array}{l}\text { The provider used open ended questions to promote the Goldilocks Effect, thereby helping the youth identify supports while also helping the } \\
\text { youth choose activities they want to do independently. They also sufficiently labeled skills as they were moving through the curriculum. }\end{array}$} \\
\hline \#4/ Positive connections & \multicolumn{2}{|c|}{$\begin{array}{l}\text { The provider helped the youth identify supports by using open ended questions, normalizing their feelings around asking for help, and using } \\
\text { the Goldilocks Effect. They also helped the youth identify ways they can asks their supports for help by using open-ended questions. }\end{array}$} \\
\hline \#4 / Improveable & \multicolumn{2}{|c|}{ The provider should avoid stacking questions, and should instead ask one open-ended question at a time. } \\
\hline \#5/ Positive connections & \multicolumn{2}{|c|}{$\begin{array}{l}\text { The provider helped the youth identify supports by using open-ended questions, normalizing their feelings around asking for help, and using } \\
\text { the Goldilocks Effect. They also helped the youth identify ways they can asks their supports for help by using open-ended questions }\end{array}$} \\
\hline $\begin{array}{l}\text { \#6 / Person-Centered Planning/AMP } \\
\text { modules }\end{array}$ & \multicolumn{2}{|c|}{$\begin{array}{l}\text { The provider helped the young person come up with an individualized plan by using open-ended questions, reflections, stiching together, and } \\
\text { guiding without leading. They kept the session conversational while staying on track }\end{array}$} \\
\hline
\end{tabular}


approach to treatment/care planning and the T2 survey included a series of questions focused on training satisfaction and feasibility. The T3 survey included the items from both the T1 and T2 survey, as well as a number of additional items. One set of additional items focused on the extent to which various aspects of the training and the organizational context acted as drivers/barriers to their use of the AMP intervention. Another set of items focused on the extent to which various elements of the training contributed to trainees' mastery. Participants were entered into a raffle to win a $\$ 100$ gift card if they completed all three surveys.

Skills self-assessment. The self-assessment of providers' skills was developed specifically for the evaluation of the AMP training, due to the absence of an existing scale to measure provider self-efficacy in implementing positive developmental, personcentered transition planning with youth and young adults. Development of the assessment followed Bandura's widely-used protocol for measuring selfefficacy in domains of interest (Bandura, 2006). Following that protocol, the research team developed sets of items focusing on providers' confidence in working with young people in a way that is consistent with each of the four key aspects of a positive developmental approach as described by Walker (2015): using a youth-/young adult-driven approach to care/treatment planning using a strengths-based approach, supporting the development of young people's self-determination skills, and supporting young people in building connections to "positive" people and community contexts. Items were also developed to assess providers' confidence in ensuring a productive collaboration between the young person and the treatment/care planning team. Each item started with the phrase How confident are you that you can... and then asked the trainee to rate their confidence level in performing that skill, using a slider bar that could be moved from $0=$ very little confidence to $100=$ complete confidence .

The sets of items from the self-assessment of skills were combined into brief scales corresponding to each of the four aspects of the positive developmental approach, plus another brief scale focused on promoting productive collaboration between the young person and the care/treatment team. Each of these brief scales had very good reliability in the current study: youth/young-adult driven approach, $\alpha=0.84$ (three items, e.g. ...help young people more clearly understand their own goals, priorities and ideas); strengths approach, $\alpha=0.84$ (three items, e.g. ...help young people identify abilities and accomplishments that they are genuinely proud of); supporting self-determination skills, $\alpha=0.85$ (three items, e.g. ...help young people learn how to take action to accomplish things they find important); building positive connections, $\alpha=0.83$ (three items, e.g... help young people learn how to build connections to positive people and organizations in their lives); and productive team collaboration, $\alpha=0.87$ (four items, e.g. ...ensure that the official team plan includes goals and activities that are meaningful to the young person). Combining all the scale scores into one overall score-i.e., by considering each of the five scale scores as an item on the overall scale-produced an overall measure of self-efficacy that also had very good internal reliability $(\alpha=0.83)$.

Training satisfaction. Trainees' satisfaction with training was assessed at $\mathrm{T} 2$ and $\mathrm{T} 3$ using items from the Impact of Training and Technical Assistance tool (Schurer Coldiron, Hensley, Walker, Estep, \& Matarese, 2016). Trainees were asked to rate the importance of training goals, the credibility of the trainers, the extent to which the training was well organized and interesting, and the overall impact of the training on their work with young people. Each of the items was rated on a scale of 1 = completely unimportant/not at all credible, etc., to $10=$ of utmost importance/exceptionally credible, etc. Using the same scale, trainees were also asked to rate how confident they were that they could apply what they were learning in their day-to-day practice. Also using the 10-point scale, trainees were asked to rate their current mastery of the kinds of skills that were being taught by the AMP trainers, and also to retrospectively rate their mastery of these skills prior to the beginning of the training. In the T3 survey, trainees were also asked to use the same 10 -point scale to rate the "overall worthwhileness" of the AMP training. 
Training transfer and learning supports. The items from the T3 survey that were related to drivers/barriers to the transfer of training into practice were prefaced by one question-How much did the following factors impact the degree to which you integrated the new information, tools and/or skills you learned from the AMP training in your work?-followed by a list of potential drivers/barriers including supervision, administrative support, and response from young people. Each of these potential drivers/ barriers was rated on a scale of $1=$ key barrier to $7=$ key driver. Similarly, trainees were asked to rate a series of items prefaced by the request Please indicate the extent to which each of these contributed to any increase in mastery you experienced, which was followed by a list of elements of the training, including example videos, AMP curriculum and related materials, and individual feedback sessions. Each of these items was rated on a 4-point scale ranging from $1=$ none to $4=$ a lot .

Scores from video recordings. As noted previously, trainers created an individualized feedback report for each video for each trainee. In addition, trainers gave overall scores for each of the final six videos for each of the same four aspects of a positive developmental approach contained on the skills self-assessment: using a youth-/young adultdriven approach to care/treatment planning, using a strengths-based approach, supporting the development of young people's self-determination skills, and supporting young people in building connections to "positive" people and community contexts. Additionally, for each video, trainees received an overall score for their ability to flexibly and appropriately implement the elements of person-centered planning that are incorporated into the AMP modules.

To ensure that videos were coded reliably, coders were trained on practice videos until they were able to match the master coding at about $90 \%$ or better for each coded category. Ongoing reliability checks of the research videos-about half were coded by the most experienced "master" coder as well as another coder-ensured that the level of match averaged above $90 \%$ across categories.

\section{Data Analyses}

To assess the extent to which trainee's confidence in each key competency area had changed during the period of training, paired samples t-tests were computed for T3 (post-training) versus T1 (pre-training) scores on the skills self-assessment. To assess these same competencies, but from an outside perspective, trainers' overall scores of trainee practice from the final video were compared to those from the third video (i.e., the first of the six full-length videos). Because the differences in T3T1 scores were not normally distributed, Wilcoxon signed tests were used to make these comparisons. However, since t-tests are relatively robust even when data are non-normal, t-tests were performed on these data as well. Effect sizes (Cohen's $d$ for dependent samples) computed for both the skills self-assessment and the video scores. Training satisfaction and implementation supports data were analyzed using simple descriptive statistics.

\section{Protection of Human Subjects}

Study procedures were approved by the institutional review board of the investigators' home university.

\section{Results}

\section{Skills Self-Assessment}

Pre- post- differences in scores for each of the subscales and the overall scale on the skills self-assessment were approximately normally distributed, so paired samples t-tests were used to determine whether trainees' scores for their confidence implementing different aspects of a positive developmental approach, as well as their scores for helping a young person work collaboratively with the treatment/care team, showed significant increases from $\mathrm{T} 1$ to $\mathrm{T} 3$. As shown in Table 1, increases were indeed significant for each subscale of the skills self-assessment, and for the overall scale. Effect sizes using Cohen's $d$ ranged from 0.50 to 1.06. Standard interpretation of Cohen's $d$ suggests that all but one of the effect sizes were large $(\geq \sim 0.8)$. 
Table 1: Paired Samples T-Tests of Pre/Post Scores from the Skills Self-Efficacy Assessment

\begin{tabular}{|c|c|c|c|c|c|c|c|c|}
\hline & \multicolumn{2}{|c|}{ Pre-Training } & \multicolumn{2}{|c|}{ Post-Training } & \multicolumn{3}{|c|}{$\begin{array}{c}\text { 95\% Confidence Interval of the } \\
\text { Difference }\end{array}$} & \multirow[t]{2}{*}{$\begin{array}{c}\text { Effect } \\
\text { Size }\end{array}$} \\
\hline & mean & SD & mean & SD & Lower & Upper & $\begin{array}{c}\text { Sig. } \\
\text { (2-tailed) }\end{array}$ & \\
\hline $\begin{array}{l}\text { Youth-/young adult-driven } \\
\text { process }\end{array}$ & 76.76 & 15.37 & 88.64 & 9.89 & 7.75 & 15.89 & 0.00 & 1.06 \\
\hline Strengths-based process & 76.91 & 15.02 & 87.22 & 11.29 & 6.14 & 14.48 & 0.00 & .92 \\
\hline $\begin{array}{l}\text { Self-determination skill } \\
\text { building }\end{array}$ & 76.37 & 15.40 & 86.02 & 13.34 & 5.90 & 13.52 & 0.00 & .94 \\
\hline Positive connections & 78.11 & 14.88 & 86.82 & 13.02 & 4.29 & 12.27 & 0.00 & .78 \\
\hline $\begin{array}{l}\text { Collaborating with } \\
\text { treatment/care team }\end{array}$ & 81.65 & 16.58 & 87.87 & 14.93 & 1.46 & 10.40 & 0.01 & .50 \\
\hline Overall & 77.96 & 14.67 & 87.31 & 11.97 & 5.53 & 12.89 & 0.00 & .95 \\
\hline
\end{tabular}

\section{Training Satisfaction}

At T2 (six weeks into the training), trainees expressed high satisfaction (i.e. means above 8.5 on the 10-point scale) with the importance of training goals and the credibility of the trainers; slightly lower satisfaction (means above 7.5 on the 10-point scale) with the organization of the training, the overall impact of the training and confidence that they could apply what they were learning in their daily work; and more moderate satisfaction (mean above 6.5 on the 10-point scale) with the extent to which the training was interesting (Table 2). Trainees' mean rating of their current mastery of skills was about 5.8 and their pre-training mastery of skills was about 4.8 on the 10-point scale. At T3 (post-training), the means for all but one of these ratings had increased; however, only two of these increases were significant: current mastery of the skills being taught, and confidence to apply what was being learned in daily work. In exception to the general trend of increases from T2 to T3, trainees' retrospective ratings of their pre-training mastery of the kinds of skills they were learning declined between $\mathrm{T} 2$ and $\mathrm{T} 3$, but not significantly.

\section{Training Transfer and Learning Supports}

The means for trainees' responses to the series of items on supports for the transfer of training into practice were all above the midpoint on the 7 -point scale, indicating that each item was seen on average to be a support (versus a barrier). As shown in Table 3 , the items that were seen as making the largest average contribution to the integration of training into practice were response from young people, usefulness of the AMP materials, response from families and/ or team members and coaching from trainers. With one exception, the remaining implementation items also had scores above 5 on the 7 -point scale. The exception was time, with a mean that was very close to the midpoint, indicating that significant numbers of trainees saw this as something of a barrier. Since responses to these items were not smoothly distributed, Table 3 also shows the percentage of respondents rating a factor as a significant barrier (rating of 1 or 2), neither a significant barrier nor a significant support (3-5), and a significant support (6 or 7). As these data show, only time was seen as a significant barrier by more than a very small number of respondents. Other factors related to the trainees' organizational context-supervision, administrative support and opinions of colleagues-were most likely to be viewed as neither a support nor a barrier. Factors related to the training itself-usefulness of AMP materials and coaching from trainers - as well as response from young people and response from families and team members, were most likely to be seen as significant supports for the transfer of training to practice. 
Table 2: Training Satisfaction

\begin{tabular}{|c|c|c|c|c|c|c|c|}
\hline & \multicolumn{2}{|c|}{ Mid-Training } & \multicolumn{2}{|c|}{ Post-Training } & \multicolumn{3}{|c|}{$\begin{array}{l}\text { 95\% Confidence Interval of the } \\
\text { Difference }\end{array}$} \\
\hline & mean & SD & mean & SD & Lower & Upper & Sig. (2-tailed) \\
\hline Importance of training goals & 8.62 & 1.56 & 8.74 & 1.48 & -0.18 & 0.77 & 0.22 \\
\hline Trainer credibility & 8.79 & 1.27 & 8.90 & 1.23 & -0.17 & 1.00 & 0.15 \\
\hline Organization of training & 7.88 & 1.90 & 8.40 & 1.31 & -0.32 & 1.07 & 0.27 \\
\hline Interest of training & 6.56 & 2.71 & 6.95 & 2.16 & -.049 & 1.27 & 0.37 \\
\hline Overall impact & 7.62 & 2.28 & 7.81 & 1.96 & -0.37 & 1.71 & 0.20 \\
\hline $\begin{array}{l}\text { Confident you can apply what } \\
\text { you are learning }\end{array}$ & 7.76 & 2.22 & 8.52 & 1.32 & 0.34 & 1.57 & 0.00 \\
\hline Current mastery of skills & 7.41 & 1.56 & 8.06 & 1.17 & -1.41 & -0.09 & 0.03 \\
\hline Pre-AMP mastery of skills & 5.88 & 2.50 & 4.81 & 2.52 & -0.27 & 1.27 & 0.19 \\
\hline
\end{tabular}

Table 3. Supports/Barriers of the Transfer of Training to Practice

\begin{tabular}{|c|c|c|c|c|c|}
\hline \multirow[b]{3}{*}{$\begin{array}{l}\text { Factors impacting the extent to which } \\
\text { training was integrated into practice }\end{array}$} & \multicolumn{5}{|c|}{ Percentage of respondents rating factor as a... } \\
\hline & & & $\begin{array}{l}\text { Significant } \\
\text { barrier }\end{array}$ & Neither & $\begin{array}{l}\text { Significant } \\
\text { support }\end{array}$ \\
\hline & mean & SD & $(1-2)$ & $(3-5)$ & $(6-7)$ \\
\hline Time & 4.18 & 1.96 & 27.7 & 36.1 & 36.2 \\
\hline Usefulness of AMP materials & 5.72 & 1.16 & 2.3 & 32.6 & 65.1 \\
\hline Supervision & 5.14 & 1.16 & 0.0 & 58.4 & 41.8 \\
\hline Administrative support & 5.02 & 1.21 & 0.0 & 60.5 & 39.6 \\
\hline Opinions of colleagues & 5.06 & 1.09 & 0.0 & 54.2 & 45.8 \\
\hline Response from young people & 5.91 & 1.02 & 0.0 & 22.9 & 77.2 \\
\hline Response from families and/or team members & 5.35 & 1.33 & 2.3 & 46.6 & 51.2 \\
\hline Coaching from trainers & 5.28 & 1.34 & 2.1 & 43.8 & 54.2 \\
\hline
\end{tabular}

The means for trainees' responses to the series of items asking about learning supports were above 3 on the 4-point scale, with one exception, background and theory, which had a mean rating of 2.85 . As shown in Table 4, the items that were seen, on average, as contributing most significantly to mastery of the material being taught, were AMP curriculum and materials and feedback calls with trainers.
Since responses to these items were not smoothly distributed, Table 4 also shows the percentage of respondents rating a learning support as contributing none/a little (rating of 1 or 2), moderately (3), or a lot (4) to mastery. These data show that, for all supports except background and theory, more than $80 \%$ of respondents saw them as contributing moderately or a lot to mastery. 
Percentage of respondents rating factor as supporting learning...

\begin{tabular}{lccccc} 
& & & $\begin{array}{c}\text { None or a } \\
\text { Little }\end{array}$ & Moderately & A lot \\
$\begin{array}{l}\text { Factors contributing to mastery of the } \\
\text { skills and knowledge being taught }\end{array}$ & mean & SD & $\mathbf{( 1 - 2 )}$ & $\mathbf{( 3 )}$ & (4) \\
\hline Background and theory & 2.85 & 0.99 & 35.4 & 33.3 & 31.3 \\
Videoconferences on basic skills & 3.19 & 0.97 & 17.0 & 36.2 & 46.8 \\
Demonstration videos & 3.15 & 0.95 & 16.7 & 41.7 & 41.7 \\
AMP curriculum and materials & 3.54 & 0.74 & 6.3 & 29.2 & 64.6 \\
Feedback reports/calls & 3.23 & 0.95 & 16.3 & 34.9 & 48.4 \\
Videoconferences on advanced skills & 3.12 & 0.91 & 16.3 & 46.5 & 37.2
\end{tabular}

\section{Scores from Video Recordings}

Results from the Kolmogorov-Smirnov test on pre- post- scores from the video recordings showed these data not to be normally distributed. As a result pre- post comparisons were made using the nonparametric Wilcoxon signed-rank test. As shown in Table 5, the tests indicated that mean competence increased significantly in each area. Table 5 also shows the results of t-tests on the same data, again showing significant pre- post- change. Effect sizes using Cohen's $d$ ranged from 0.66 to 1.26 . Standard interpretation of Cohen's $d$ suggests that all but one of these effect sizes were large $(\geq \sim 0.8)$.

\section{Discussion}

Findings from this study lend support to the hypothesis that the AMP remote training and coaching increases mental health providers' skill in implementing a set of common elements (i.e., the steps in a structured process of personcentered planning) that are found frequently across empirically-supported approaches for working with emerging adults with serious mental health conditions. The AMP remote approach also appears effective in increasing providers' skills for working with young people in a way that is consistent with a set of common factors or practice principles.

Table 5. Paired Sample Tests on Scores from Video Recordings

\begin{tabular}{lccccc}
\hline & Wilcoxon signed rank & Paired samples t-test & Effect Size \\
& $\mathbf{Z}$ & $\begin{array}{c}\text { Significance } \\
\text { (2-tailed) }\end{array}$ & $\mathbf{t}$ & $\begin{array}{c}\text { Significance } \\
\text { (2-tailed) }\end{array}$ \\
\hline Youth-/young adult-driven process & -5.51 & 0.00 & 8.17 & 0.00 & 1.03 \\
Strengths-based process & -4.86 & 0.00 & 6.11 & 0.00 & .71 \\
Self-determination skill building & -4.43 & 0.00 & 5.31 & 0.00 & .66 \\
Positive connections & -5.19 & 0.00 & 6.94 & 0.00 & .94 \\
Person-Centered Planning/AMP modules & -5.38 & 0.00 & 7.37 & 0.00 & .98 \\
Overall & -6.16 & 0.00 & 9.42 & 0.00 & 1.26
\end{tabular}


Specifically, the study supports the proposition that the AMP remote training can increase providers' skills for working with young people in a manner that is strengths based and driven by the young person's perspectives and priorities, and that promotes young people's skills for self-determination and for building connections to individuals and contexts that support positive development.

The findings also provide evidence for the usefulness of a purely remote training and coaching process that incorporates training best practices to an extent that significantly exceeds what is typical for trainings offered in community mental health settings. In contrast to the consecutive-day workshop format with no opportunity for observation and feedback, the AMP remote training offers a number of advantages, among them: the opportunity for trainees to see their own practice on video; observation-based coaching using samples of actual practice with young clients; feedback based on objective criteria; opportunities for trainees to view recordings of expert practice; and continued coaching and remediation until trainees achieved benchmark levels of skill. Overall, the AMP remote training consumed about 20 hours of trainees' time over a period of approximately 4 months, and yet also appeared to bring about significant practice change, as assessed both objectively-by ratings of video-recorded practice-and subjectively-by trainees' ratings of their own skill. Thus the invested time per trainee is about 2.5 days total-which would be very short for a workshop-type training event-and the training did not have any costs related to transportation, per diem or lodging.

Participants were quite satisfied with the training, and their satisfaction generally trended upward between the midpoint of the training and the post-training assessment. They also expressed a high level of confidence that they would be able to apply what they were learning in their day-to-day practice. What is more, this confidence increased significantly between the early assessment and the post-training assessment.

More than three quarters of participants said that the response of young people was a significant factor supporting their use of AMP in their practice, and nearly two thirds of participants found the AMP materials to be a significant support for the transfer of training to practice. Coaching from the trainers and the response from families/treatment team members were also seen as a significant support for training transfer by more than half of the trainees. On the other hand, well over half of the participants saw their supervisors as not significantly supporting their use of AMP in daily practice, though supervisors were not seen as barrier either. Similarly, the majority of trainees saw administrators as neither a support nor a barrier to training transfer. Time was seen as the biggest barrier to the transfer of training to practice. On average, trainees rated the AMP curriculum and materials as the factor contributing most significantly to their mastery of the skills and knowledge being taught, followed by the feedback calls and reports, and videoconferences on basic skills.

There are of course significant limitations that should be kept in mind when considering the findings from the study. The most obvious of these is the relatively small scale of the study. Further research will be needed to see if the findings can be replicated more broadly. Additional study will also be required in order to learn about what sort of additional follow-up coaching and training-and what kind of support to supervisors and agencies more broadlywill be required to sustain training gains. Another limitation is related to characteristics of the trainees. While information about academic credentials and general information about their time the current position was collected, other variables of potential interest were not. However, the small scale of the study would have precluded analysis based on other personal characteristics. The absence of detailed information on providers' personal characteristics also means it is not possible to make comparisons between those who completed the training and the $18 \%$ who were reassigned or who left their jobs. Again, however, the small overall sample size would have made meaningful comparisons unlikely. An $18 \%$ turnover rate in and of itself is not anomalous for this workforce (Walker, 2017). The absence of a control group is a further limitation. It is possible, for example that participants' self-assessments of their skills increased simply because they knew they were participating in a skills-enhancement 
training. However, findings from the video scores provides evidence suggesting that real learning did indeed occur. Additionally, while the study findings provide relatively robust evidence of an impact on trainees' practice, the study did not assess whether this change in practice led to increases in young people's levels of engagement or retention in services, or their positive development or functioning. Additional research will be required to test whether trainee-level impacts will be associated with measurable improvements in young people's lives. Finally, while the study utilized remote training strategies that are thought to have the potential to be highly cost effective, costs were not actually measured in the study. Future research will be needed in order to capture cost data and compare it with costs of alternative training approaches.

Overall, the findings from this study align with research trends suggesting that the future will likely see the continued social innovation around strategies for training mental health providers. Separately or in combination, remote coaching strategies and strategies based on common factors and elements offer training options that may transform current training practices. It is exciting to contemplate a future in which persistent training barriers have been overcome, and providers have enhanced opportunities to acquire the skills and competencies they need in order to do their work effectively.

\section{References}

Aarons, G. A., Wells, R. S., Zagursky, K., Fettes, D. L., \& Palinkas, L. A. (2009). Implementing evidencebased practice in community mental health agencies: A multiple stakeholder analysis. American Journal of Public Health, 99(11), 2087-2095. https:// doi.org/10.2105/AJPH.2009.161711.

Achieve My Plan. Retrieved from https://achievemyplan. pdx.edu/amp-wraparound.php (January 29, 2019).

Ardito, R. B., \& Rabellino, D. (2011). Therapeutic alliance and outcome of psychotherapy: Historical excursus, measurements, and prospects for research. Frontiers in Psychology, 2, 1-11. https://doi.org/10.3389/ fpsyg.2011.00270.

Arnett, J. J. (2000). Emerging adulthood: A theory of development from the late teens through the twen- ties. American Psychologist, 55(5), 469-480. https:// doi.org/10.1037//0003-066X.55.5.469.

Arnett, J. J. (2007). Suffering, selfish, slackers? Myths and reality about emerging adults. Journal of Youth and Adolescence, 36(1), 23-29. https://doi.org/10.1007/ s10964- 006-9157-z.

Baggio, S., Studer, J., Iglesias, K., Daeppen, J.-B., \& Gmel, G. (2016). Emerging adulthood. Evaluation \& the Health Professions, 40(4). https://doi.org/10.1177/ 0163278716663602016327871666360.

Bandura, A. (2006). Guide for Constructing Self-Efficacy Scales. In Frank Pajares, \& Tim Urdan (Eds.). Selfefficacy beliefs of adolescents (pp. 307-337). Greenwich, CT: Information Age Publishing.

Barth, R. P., Lee, B. R., Lindsey, M. A., Collins, K. S., Strieder, F., Chorpita, B. F., \& Sparks, J. A. (2011). Evidence-based practice at a crossroads: The timely emergence of common elements and common factors. Research on Social Work Practice, 22(1), 108119. https://doi.org/10.1177/1049731511408440.

Bond, G. R., Drake, R. E., McHugo, G. J., Peterson, A. E., Jones, A. M., \& Williams, J. (2014). Long-term sustainability of evidence-based practices in community mental health agencies. Administration and Policy in Mental Health and Mental Health Services Research, 41(2), 228-236. https://doi.org/10.1007/ s10488-012-0461-5.

Bruns, E. J., Walker, J. S., Bernstein, A., Daleiden, E., Pullmann, M. D., \& Chorpita, B. F. (2014). Family voice with informed choice: Coordinating Wraparound with research-3based treatment for children and adolescents. Journal of Clinical Child and Adolescent Psychology, 43(2), 256-269. https://doi.org/10.1080/ 15374416.2013.859081.

Catalano, R. F., Berglund, M. L., Ryan, J. A. M., Lonczak, H. S., \& Hawkins, J. D. (2004). Positive youth development in the United States: Research findings on evaluations of positive youth development programs. The Annals of the American Academy of Political and Social Science, 591(1), 98-124. https:// doi.org/10.1177/0002716203260102.

Chorpita, B. F., Bernstein, A., \& Daleiden, E. L. (2011). Empirically guided coordination of multiple evidence-based treatments: An illustration of relevance mapping in children's mental health services. Journal of Consulting and Clinical Psychology, 79(4), 470-480. https://doi.org/10.1037/a0023982. 
Chorpita, B. F., Daleiden, E. L., \& Weisz, J. R. (2005). Identifying and selecting the common elements of evidence based interventions: A distillation and matching model. Mental Health Services Research, 7(1), 5-20. https://doi.org/10.1007/s11020-005-1962-6.

Clark, H. B., \& Unruh, D. K. (2009). Understanding and addressing the needs of transition-age youth and young adults and their families. Transition of youth and young adults with emotional or behavioral difficulties: An evidence-supported handbook (pp. 3-24). Baltimore, MD: Brookes Publishing.

Dorsey, S., Pullmann, M. D., Deblinger, E., Berliner, L., Kerns, S. E., Thompson, K., \& Garland, A. F. (2013). Improving practice in community-based settings: A randomized trial of supervision - study protocol. Implementation Science: IS, 8, 89. https:// doi. org/10.1186/1748-5908-8-89.

Drake, R. E., Goldman, H. H., Leff, H. S., Lehman, A. F., Dixon, L., Mueser, K. T., \& Torrey, W. C. (2011). Implementing evidence-based practices in routine mental health service settings. Psychiatric Services, 52(2), 179-182.

Edmunds, J. M., Beidas, R. S., \& Kendall, P. C. (2013). Dissemination and implementation of evidencebased practices: Training and consultation as implementation strategies. Clinical Psychology: Science and Practice, 20(2), 152-165. https://doi. org/10.1111/ cpsp.12031.

Ellison, M. L., Klodnick, V. V., Bond, G. R., Krzos, I. M., Kaiser, S. M., Fagan, M. A., \& Davis, M. (2015). Adapting supported employment for emerging adults with serious mental health conditions. The Journal of Behavioral Health Services \& Research, 42(2), 206-222. https://doi.org/10.1007/ s11414-014-9445-4.

Garland, A. F., Haine-Schlagel, R., Brookman-Frazee, L., Baker-Ericzen, M., Trask, E., \& Fawley-King, K. (2013). Improving community-based mental health care for children: Translating knowledge into action. Administration and Policy in Mental Health, 40(1), 6-22. https://doi.org/10.1007/s10488-012-0450-8.

Goense, P. B., Boendermaker, L., \& van Yperen, T. (2016). Support systems for treatment integrity. Research on Social Work Practice, 26(1), 69-73. https://doi. org/10.1177/ 1049731515579205.

Haber, M. G., Cook, J. R., \& Kilmer, R. P. (2012). Perceptions of family environment and wraparound processes: Associations with age and implica- tions for serving transitioning youth in systems of care. American Journal of Community Psychology, 49(3-4), 454-466. https://doi.org/10.1007/ s10464-012-9490-1.

Haber, M. G., Karpur, A., Deschênes, N., \& Clark, H. B. (2008). Predicting improvement of transitioning young people in the partnerships for youth transition initiative: Findings from a multisite demonstration. The Journal of Behavioral Health Services \& Research, 35(4), 488-513. https://doi.org/10.1007/ s11414-008-9126-2.

Hawley, K. M., \& Garland, A. F. (2008). Working alliance in adolescent outpatient therapy: Youth, parent and therapist reports and associations with therapy outcomes. Child and Youth Care Forum, 37(2), 59-74. https://doi.org/10.1007/s10566-008- 9050-x.

Herschell, A. D., Kolko, D. J., Baumann, B. L., \& Davis, A. C. (2010). The role of therapist training in the implementation of psychosocial treatments: A review and critique with recommendations. Clinical Psychology Review, 30(4), 448-466. https://doi.org/ 10.1016/j. cpr.2010.02.005.

Institute of Medicine and National Research Council (2015). Investing in the health and well-being of young adults. Washington DC: National Academies Press. https://doi.org/10.17226/18869.

Jivanjee, P., Brennan, E., Grover, L., \& Thorp, K. (2018). What do transition service providers need to know and be able to do? Results of a national survey of training needs and preferences. Portland, OR: Research and training Center for Pathways to Positive Futures, Portland State University.

Kim, H., Munson, M. R., \& McKay, M. M. (2012). Engagement in mental health treatment among adolescents and young adults: A systematic review. Child and Adolescent Social Work Journal, 29(3), 241-266. https://doi.org/10.1007/s10560-012-0256-2.

Kruger, J., \& Dunning, D. (1999). Unskilled and unaware of it: How difficulties in recognizing one's own incompetence lead to inflated self-assessments. Journal of Personality and Social Psychology, 77(6), 11211134. https://doi.org/10.1037/0022- 3514.77.6.1121.

Lang, J. M., \& Connell, C. M. (2017). Measuring costs to community-based agencies for implementation of an evidence-based practice. The Journal of Behavioral Health Services and Research, 44(1), 122-134. https://doi.org/10.1007/s11414-016-9541-8. 
Lerner, R. M., Brentano, C., Dowling, E. M., \& Anderson, P. M. (2002). Positive youth development: Thriving as the basis of personhood and civil society. New Directions for Youth Development: Pathways to Development among Diverse Youth, 95, 11-33.

Martino, S., Ball, S., Nich, C., Frankforter, T. L., \& Carroll, K. M. (2009). Correspondence of motivational enhancement treatment integrity ratings among therapists, supervisors, and observers. Psychotherapy Research: Journal of the Society for Psychotherapy Research, 19 (March 2014), 181-193. https://doi. org/10.1080/10503300802688460.

Martino, S., Paris, M., Añez, L., Nich, C., Canning-Ball, M., Hunkele, K., \& Carroll, K. M. (2016). The effectiveness and cost of clinical supervision for motivational interviewing: A randomized controlled trial. Journal of Substance Abuse Treatment, 68, 11-23. https://doi.org/10.1016/j.jsat.2016.04.005.

Miller, E., Stanhope, V., Restrepo-Toro, M., \& Tondora, J. (2017). Person-centered planning in mental health: A transatlantic collaboration to tackle implementation barriers. American Journal of Psychiatric Rehabilitation, 20(3), 251-267. https://doi.org/10.1080/1 5487768.2017 .1338045 .

Milne, D., Sheikh, A., Pattison, S., \& Wilkinson, A. (2011). Evidence-based training for clinical supervisors: A systematic review of 11 controlled studies. The Clinical Supervisor, 30(1), 53-71. https://doi.org /10.1080/07325223.2011.564955.

Mitchell, P. F. (2011). Evidence-based practice in realworld services for young people with complex needs: New opportunities suggested by recent implementation science. Children and Youth Services Review, 33(2), 207-216. https://doi.org/10.1016/j. childyouth.2010.10.003.

Moore, K. L. (2018). Mental health service engagement among underserved minority young adults: A systematic review. Journal of Racial and Ethnic Health Disparities, 5, 1063-1076.

Olmstead, T. A., Abraham, A. J., Martino, S., \& Roman, P. M. (2012). Counselor training in several evidencebased psychosocial addiction treatments in private US substance abuse treatment centers. Drug and Alcohol Dependence, 120(1-3), 149-154. https:// doi. org/10.1016/j.drugalcdep.2011.07.017.

Parsons, M. B., \& Reid, D. H. (2012). Evidence-based staff training: A guide for practitioners. Behavior Analysis in Practice, 5(2), 2-11. https://doi.org/10.1007/ BF03391819.
Pottick, R., Bilder, S., \& Vander Stoep, A. (2008). US patterns of mental health service utilization for transition-age youth and young adults. Journal of Behavioral Health Services \& Research, 35(4), 373-389.

Powell, B. J., Proctor, E. K., \& Glass, J. E. (2013). A systematic review of strategies for implementing empirically supported mental health interventions. Research on Social Work Practice, 24(2), 192-212. https://doi.org/10.1177/1049731513505778.

Rakovshik, S. G., \& McManus, F. (2010). Establishing evidence-based training in cognitive behavioral therapy: A review of current empirical findings and theoretical guidance. Clinical Psychology Review, 30(5), 496-516. https://doi.org/10.1016/j. cpr.2010.03.004.

Rosenberg, L. (2016). Bridging the gap between adolescence and adulthood: The challenges of emerging adults. The Journal of Behavioral Health Services \& Research, 43(4), 518-520. https://doi.org/10.1007/ s11414-016-9535-6.

Roundfield, K. D., \& Lang, J. M. (2017). Costs to community mental health agencies to sustain an evidencebased practice. Psychiatric Services, 23(4), https:// doi.org/10.1176/appi.ps.201600193appi.ps.2016001.

Schurer Coldiron, J., Hensley, S., Walker, J. S., Estep, K., \& Matarese, M. (2016). The revision and application of a training impact survey for Wraparound. Portland, OR: National Wraparound Initiative, Portland State University. Retrieved from https:// nwi.pdx.edu/pdf/ IOTTA-Training-Survey-Wraparound.pdf.

Shirk, S. R., \& Karver, M. (2003). Prediction of treatment outcome from relationship variables in child and adolescent therapy: A meta-analytic review. Journal of Consulting and Clinical Psychology, 71, 452-464.

Sinclair, S., \& Baglioni, S. (2014). Social innovation and social policy-Promises and risks. Social Policy and Society, 13(3), 409-410.

Stein, K. F., Connors, E. H., Chambers, K. L., Thomas, C. L., \& Stephan, S. H. (2014). Youth, caregiver, and staff perspectives on an initiative to promote success of emerging adults with emotional and behavioral disabilities. The Journal of Behavioral Health Services \& Research. https://doi.org/10.1007/ s11414-014-9426-7.

Stewart, K. D. (2013). Factors contributing to engagement during the initial stages of treatment for psy- 
chosis. Qualitative Health Research, 23(3), 336-347. https://doi.org/ 10.1177/1049732312468337.

Stirman, S. W., Langdon, K., \& Graham, J. R. (2016). Bridging the gap between research and practice in mental health service settings: An overview of developments in implementation theory and research. Behavior Therapy, 47(6), 920-936. https:// doi.org/10.1016/j.beth.2015.12.001.

Stone, A. A., Schwartz, J. E., Broderick, J. E., \& Deaton, A. (2010). A snapshot of the age distribution of psychological well-being in the United States. Proceedings of the National Academy of Sciences, 107(22), 99859990. https://doi.org/10.1073/pnas.1003744107.

Substance Abuse and Mental Health Services Administration (2018). Key Substance Use and Mental Health Indicators in the United States: Results from the 2017 National Survey on Drug Use and Health. Rockville, MD. Author. Retrieved from https://www.

Taylor, J. E., \& Taylor, J. A. (2013). Person-centered planning: Evidence-based practice, challenges, and potential for the 21st century. Journal of Social Work in Disability \& Rehabilitation, 12(3), 213-235. https://doi.org/10.1080/1536710X.2013.810102.

US Government Accountability Office (2008). Young adults with serious mental illness: Some states and federal agencies are taking steps to address their transition challenges. Washington DC: Author.

Walker, J. S. (2015). A theory of change for positive developmental approaches to improving outcomes among emerging adults with serious mental health conditions. The Journal of Behavioral Health Services \& Research, 42(2), 131-149. https://doi.org/10. 1007/s11414-015-9455-X.

Walker, Janet S., Brennan, Eileen M., Jivanjee, Pauline, Koroloff, Nancy, \& Moser, Celeste L. (2015). Introduction to the special issue: Empirically-based interventions for emerging adults with serious mental health conditions. The Journal of Behavioral Health Services \& Research, 42(2), 127-130. https://doi. org/10.1007/s11414-015- 9456-9.

Walker, J. S., \& Flower, K. M. (2015). Provider perspectives on principle-adherent practice in empiricallysupported interventions for emerging adults with serious mental health conditions. The Journal of Behavioral Health Services \& Research, 43(4), 525541. https://doi.org/10.1007/s11414-015-9465-8.

Walker, J. S., \& Gowen, L. K. (2011). Community-based approaches for supporting positive development in youth and young adults with serious mental health conditions. Portland, OR: Research and Training Center for Pathways to Positive Futures, Portland State University.

Walker, J. S., \& Gowen, L. K. (2012). Transition education for adolescents with serious mental health conditions. In Michael L. Wehmeyer, \& Kristine W. Webb (Eds.). Handbook of transition education for youth with disabilities. New York: Routledge.

Walker, J. S., Pullmann, M. D., Moser, C. L., \& Bruns, E. J. (2012). Does team-based planning "work" for adolescents? Findings from studies of Wraparound. Psychiatric Rehabilitation Journal, 35(3), 189-197. https://doi.org/10.2975/35.3.2012.189.198.

Walker, J. S., Schurer Coldiron, J., \& Taylor, E. (2017). Turnover among wraparound care coordinators: Stakeholders' views on causes, impacts, and remedies. Baltimore, MD: The National Technical Assistance Network for Children's Behavioral Health.

Walker, J. S., \& Schutte, K. (2005). Quality and individualization in wraparound team planning. Journal of Child and Family Studies, 14(2), 251-267. https:// doi.org/10. 1007/s10826-005-5052-6.

Walker, J. S., \& Schutte, K. M. (2004). Practice and process in Wraparound planning. Journal of Emotional and Behavioral Disorders, 12(3), 182-192. https:// doi.org/10. 1177/10634266040120030501.

Walker, J. S., Seibel, C. L., \& Jackson, S. (2017). Increasing youths' participation in team- based treatment planning: The Achieve My Plan enhancement for Wraparound. Journal of Child and Family Studies, 8(26). https://doi.org/10.1007/s10826-017-0738-0.

Walker, J. S., Seibel, C. L., Jackson, S., \& Ossowski, J. D. (2016). Introduction to the special section on positive developmental strategies for engaging emerging adults and improving outcomes. The Journal of Behavioral Health Services \& Research, 3-6. https:// doi.org/10.1007/s11414-016-9524-9.

Weisz, J. R., Chorpita, B. F., Palinkas, L. A., Schoenwald, S. K., Miranda, J., Bearman, S. K., \& Mayberg, S. (2012). Testing standard and modular designs for psychotherapy treating depression, anxiety, and conduct problems in youth: A randomized effectiveness trial. Archives of General Psychiatry, 69(3), 274-282. https://doi.org/10. 1001/ archgenpsychiatry.2011.147. 
Weisz, J. R., Jensen-Doss, A., \& Hawley, K. M. (2006). Evidence-based youth psychotherapies versus usual clinical care: A meta-analysis of direct comparisons. The American Psychologist, 61(7), 671-689. https:// doi.org/10.1037/0003-066X.61.7.671.
Zack, S. E., Castonguay, L. G., \& Boswell, J. F. (2007). Youth working alliance: A core clinical construct in need of empirical maturity. Harvard Review of Psychiatry, 15(6), 278-288. https://doi. org/10.1080/10673220701803867.

[This is an accepted manuscript of an article published by Elsevier in Children \& Youth Services Review May 2019, available online: https://doi.org/10.1016/j.childyouth.2019.02.040]

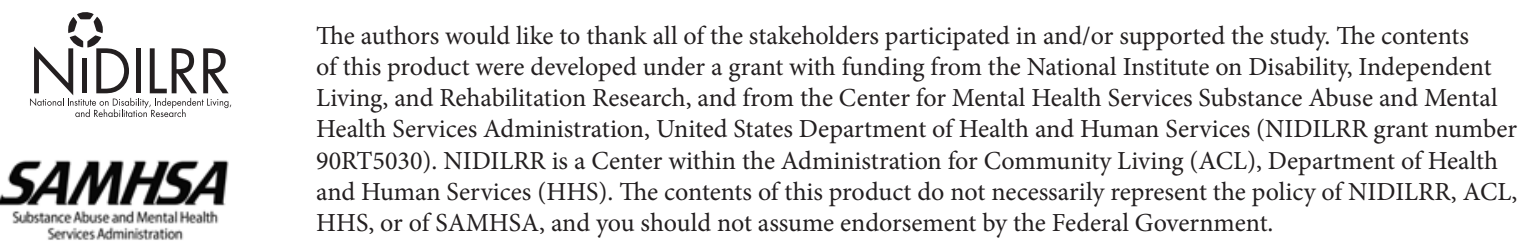

